\title{
High Spatial Resolution Evaluation of Residual Stresses in Shot Peened Specimens Containing Sharp and Blunt Notches by Micro-hole Drilling, Micro-slot Cutting and Micro-X-ray Diffraction Methods
}

\author{
B. Winiarski ${ }^{1,2} \cdot$ M. Benedetti ${ }^{3}$ - V. Fontanari $^{3}$ - M. Allahkarami ${ }^{4}$ - J.C. Hanan ${ }^{4}$. \\ P.J. Withers ${ }^{1}$
}

Received: 29 October 2015 / Accepted: 31 May 2016/Published online: 10 June 2016

(C) The Author(s) 2016. This article is published with open access at Springerlink.com

\begin{abstract}
The moderately high lateral RS gradients (on the order of tens of $\mathrm{MPa} / \mu \mathrm{m}$ ) near shot peened notches in conjunction with the shallow treatment depth (some hundreds of microns) limit the application of far-field and/or high resolution synchrotron diffraction residual stress measurement techniques. Recently proposed Focused Ion Beam - Scanning Elecron Microscope - Digital Image Correlation (FIB-SEMDIC) based micro mechanical stress relaxation methods for the measurement of residual stress at the micron scale became suitable techniques for local evaluation of residual stresses and stress gradients in shot peened specimens. In this paper ultra-high resolution $(\sim 0.5-0.8 \mu \mathrm{m}$ depth and $5-10 \mu \mathrm{m}$ lateral resolution) mechanical relaxation stress measurements were used to evaluate the stress variation local to individual peening dimples in ceramic $(60-120 \mu \mathrm{m}$ diameter beads) shot peened Al-7075-T651 double notched samples having 0.15, 0.5 and $2.0 \mathrm{~mm}$ radii using Micro-Hole Drilling ( $\mu \mathrm{HD})$, Micro-Slot Cutting ( $\mu \mathrm{SC})$ and micro X-ray Diffraction ( $\mu \mathrm{XRD})$ methods. The micron-sized sampling volumes enabled the stress to be evaluated in individual impact craters (dimples) showing
\end{abstract}

B. Winiarski

B.Winiarski@manchester.ac.uk; Bartlomiej.Winiarski@FEI.com

1 Henry Moseley X-ray Imaging Facility, School of Materials, The University of Manchester, Manchester M13 9PL, UK

2 FEI Company, Achtseweg Noord 5, Bldg 5651 GG, Eindhoven, The Netherlands

3 Department of Industrial Engineering, University of Trento, Via Sommarive 9, 38123 Trento, Italy

4 Department of Mechanical and Aerospace Engineering, Oklahoma State University, 700 N. Greenwood Ave., 74106 Tulsa, OK, USA significant point-to-point variation $(\sim+/-150 \mathrm{MPa})$ (with certain dimples even recording tensile stresses). After around $30 \mu \mathrm{m}$ of layer removal the heavily deformed region had largely been removed and the stress profile became much more homogeneous. At this depth the $\mu \mathrm{HD}$ and $\mu \mathrm{SC}$ results were in good accord with those from $\mu$ XRD measurements which sample over a much larger volume ( $\sim 40 \mu \mathrm{m}$ depth $\times$ $50 \mu \mathrm{m}$ laterally) showing an in-plane compressive stress of around $150 \mathrm{MPa}$ far from the notches with the residual stress rising to about $200 \mathrm{MPa}$ at a blunt $(2 \mathrm{~mm})$ notch and $500 \mathrm{MPa}$ for a sharp $(0.15 \mathrm{~mm})$ one. Further, these recorded variations of residual stresses were correlated with microstructural features, e.g. grains, networks of sub-surface cracks, intermetallics and highly deformed sub-surface regions, revealed by large volume Serial Sectioning Tomography using Plasma $\mathrm{Xe}^{+}$Focus Ion Beam - Scanning Electron Microscope (PFIB-SEM), EDS and EBSD maps. This allowed for the first time characterize large volume $\left(100 \times 66 \times 30 \mu^{3}\right)$ of shot peened regions with resolution of dozens of nanometers and correlate residual stress depth profiles with 3D microstructural features. Finally, in (Benedetti et al. 2016, Int. J. Fatigue) these RS measurements are used to reconstruct the RS field through finite element (FE) analyses.

Keywords XRD $\cdot$ Focused ion beam (FIB) micro-slot cutting $\cdot$ FIB micro-hole drilling $\cdot$ Shot peening · Al-7075-T651 · Residual stress · Plasma Xe ${ }^{+}$FIB-SEM . Serial sectioning tomography

\section{Introduction}

Residual stresses (RS) are induced by almost all component manufacturing and surface finishing processes, e.g. metal 
forming, casting, welding, polishing, etc. [1]. In many cases they can be neglected but in others they can significantly extend or shorten component lifetimes. For large components they can vary over meter dimensions but they can also be present at the micron scale. Such stresses can significantly affect the performance of thin-films [2,3] peened layers, bump-bonded electronic devices [4], micro/nano-electro-mechanical systems (MEMS/NEMS) [5], etc.

If introduced carefully RS can also help to prolong fatigue lifetimes. This is usually done by establishing compressive RSs near the component surface and can be especially beneficial near stress concentrators or notches, such as shouldered shafts, riveted aeronautical panels, gears, etc. [6, 7]. For this purpose, RSs are frequently introduced by shot peening (SP), because it can treat, with near-full coverage, geometrical details that are inaccessible to other surface treatments, like hammer or ultrasonic peening or ball burnishing. Unsurprisingly, the benefit arising from SP is strongly correlated to the depth and extent of the RS produced by the treatment [8]. Therefore, in recent years, there has been increasing interest in explicitly including the effects of SP process into life assessment models rather than considering SP simply as an additional safety factor [9]. Specifically, RS produced by shot peening are incorporated into multiaxial fatigue criteria, sometimes in combination with critical distance approaches [7, 10, 11], or into damage tolerant approaches [12-14]. In the former, the RSs are treated as mean biaxial stresses superimposed on the stress field produced by external loading, in the latter case, the RSs are included as R-ratio and crack closure effects. In the vast majority of cases, RSs are estimated through experimental measurements taken on flat unnotched coupons using laboratory incremental layer removal X-ray diffraction (XRD) $[15,16]$, incremental blind hole drilling $[17,18]$, synchrotron X-ray $[19,20]$ or neutron diffraction [21].

Despite the importance of this topic for the structural integrity assessment of shot peened components, very few papers in the literature dealt with the determination of the RS distribution near peened notches. To authors' knowledge, correlation of residual stresses with three-dimensional microstructural features of the shot peened surface layers near notches (with sub-micron size features) down to the parent microstructure near peened notches has not been performed yet. Explicit dynamic finite element (FE) simulation of the SP process proved to be an effective way of estimating RS [22, 23], but, to the best of our knowledge, simulations have only considered flat target surfaces and no one attempted to simulate the multiple shot impacts onto complex geometrical details. Bagherifard et al. [11] tried to predict the fatigue resistance of peened notched parts measuring RSs far from the notch, thus neglecting the perturbation exerted by the notch on the RS field in terms of intensity and mono- or multi-axiality. Laboratory XRD measurements were taken on the root of peened notches [24-28], but the millimeter size of the irradiated area impeded to resolve the lateral gradient of the RS distribution. King et al. [29] used energy dispersive synchrotron XRD to measure inplain residual strains at the root of the notch of shot peened samples. In this way, in-depth residual strain profiles could be measured without surface layer removal, but the large size of the gauge volume along the incident beam direction ( $40 \%$ of the specimen thickness) prevented the lateral residual strain gradient to be measured. Jun et al. [30] used synchrotron XRD to measure residual strains on shot peened conical samples and attempted to reconstruct the residual stress field using eigenstrain inverse analysis based on the assumption that the eigenstrain distribution depends only on the depth below the treated surface: the agreement between modeled and measured strains was good far from the cone tip, while close to the cone tip the agreement was less satisfactory, apparently due interaction between the treated surfaces. In other applications [7, 31], RS in peened notches samples are indirectly estimated using the inverse eigenstrain analysis, wherein the eigenstrain distribution is inferred from experimental measures taken on flat samples and then transferred to different, even notched, geometries, but no experimental verification of the estimated RS state was provided.

Considerable experimental challenges are encountered when measuring RSs at the tip of shot peened notches. Some of them are typical of plain peened samples too, such as a shallow treatment depth (some hundreds of microns) with intense in-depth high RS gradients (on the order of tens of $\mathrm{MPa} / \mu \mathrm{m}$ ), surface roughness and inhomogeneous surface layers affected by the peening treatment. These issues make in most cases far-field techniques, such as the contour method [32] and the slitting technique [33], unsuitable. Other difficulties stem from the noticeable perturbation exerted by the notch on the RS field, resulting in considerable lateral gradients (on the order of tens of $\mathrm{MPa} / \mu \mathrm{m}$ ), as well as from the fact that notches are frequently located at the intersection of peened surfaces, hence the RS field is affected by the interaction between the plastic strain fields produced on the outer layers of the treated surfaces. In view of these considerations, blindhole-drilling [34], conventional X-ray [35] and neutron diffraction [36] appear to be not suitable, since they probe regions of millimetre dimensions, which are too large to resolve steep lateral RS gradients. Residual strain measurements with high lateral spatial resolution have been already done in the past using synchrotron XRD, mainly to determine crack-tip strain fields [37-40]. However, as high energy XRD utilizes small diffraction angles, the very high lateral spatial resolution can usually only be achieved in two orthogonal directions at the centre of bulk specimens. This is acceptable in the case of sufficiently thick specimens, since near-plane strain conditions prevail almost throughout the specimen thickness. On the contrary, this poses considerable experimental challenges if near-surface RS fields must be measured on peened notched 
specimens. In addition, synchrotron radiation is only available in few central facilities around the world. The beam time is limited typically to few weeks around the year. Such an expensive and limited facility that needs a high level of expertise is not a viable option for routine measurements, as those required for fatigue life calculation of peened mechanical members.

Recent Focused Ion Beam - Scanning Electron Microscope - Digital Image Correlation (FIB-SEM-DIC) based micro mechanical stress relaxation methods for the measurement of residual stress at the micron scale [41-45] and X-ray micro-diffraction became suitable techniques for local evaluation of residual stresses and stress gradients in shot peened specimens in a laboratory environment. Accordingly, micro-slot cutting ( $\mu \mathrm{SC})$, and micro-hole drilling $(\mu \mathrm{HD})$ and micro X-Ray Diffraction ( $\mu \mathrm{XRD})$ techniques with micronsized gauge volumes are used to resolve the expected high RS gradients. In contrast to conventional XRD, the term $\mu \mathrm{XRD}$ refers to the use of an X-ray beam with diameter of $500 \mu \mathrm{m}$ and below. Laboratory instruments for $\mu \mathrm{XRD}$ employ - besides standard sealed tubes - microfocus and rotating anode X-ray sources in order to provide the highest available flux density. Despite these efforts the diffracted intensity can still be very weak and 1D or 2D dimensional detectors are therefore used to increase the measurement signal or reduce the measurement time. Last but not least combined lasersystems ensure the correct measurement spot on the sample as well as automatic sample alignment using pattern recognition. $\mu \mathrm{SC}[43,45]$ and $\mu \mathrm{HD}[41,42,44]$ are mechanical relaxation methods that have been down-sized to the micron scale using focused ion beam to mill holes, slots, cores, etc. SEM column is used to collect series of image before and after FIB milling. 2-D displacement/strains fields are calculated from SEM images using DIC cross-correlation and later stresses are estimated from these fields using suitable algorithms aided often with Finite-Element Analysis data. These methods have significantly different sampling volumes; micro mechanical relaxation methods can measure stresses with submicron depth and 5-10 $\mu \mathrm{m}$ lateral resolution [46], while $\mu$ XRD samples tens of micron both in-depth and laterally [47]. Consequently the former may be able to resolve the point to point variations local to specific shot peening dimples whereas the latter provides a volume averaged response.
While the micro ring-core method has been compared with XRD for crystalline thin films [48], relatively few comparative studies have been undertaken for the $\mu \mathrm{HD}$ and $\mu \mathrm{SC}$ methods.

In the present paper, we (1) investigate and compare the applicability of the three micron-scale laboratory experimental techniques to the measurement of RSs close to the notch tip of shot peened prismatic Al-7075-T651 specimens carrying two edge V-notches. Of particular interest here are: (2) the capability of the micro mechanical methods to measure the RSs local to individual dimples and their sensitivity to inhomogeneities introduced by the gentle bead-peening treatment into the surface layers; and (3) correlation the measured residual stress surface and depth profiles with microstructural features (grains, voids, micro-cracks, intermetallics, etc.) in 2D and 3D identified by Plasma $\mathrm{Xe}^{+}$FIB assisted large volume serial sectioning tomography, Energy-dispersive X-ray spectroscopy (EDS) and Electron Backscatter Diffraction (EBSD) maps. In our companion paper [49], the linescan measurements undertaken in the present work are used to reconstruct the RS field near the notch tips through finite element analyses.

\section{Materials and Methods}

A $4 \mathrm{~mm}$ thick rolled plate of aeronautical grade aluminium alloy Al-7075-T651 was used in these investigations. Metallographic analyses conducted in [50] on the base material revealed equiaxial pancake grains of average size of about $70 \mu \mathrm{m}$ on the rolling plane and highly elongated grains of about $10 \mu \mathrm{m}$ thickness on the trough-thickness cross-section. Double V-edge notched specimens were electro-discharge machined (EDM) from the plate (Fig. 1) according to the ISO 3928 standard, with the notch fillet radii $\mathrm{R}$ of $2 \mathrm{~mm}$ (blunt notch), $0.5 \mathrm{~mm}$ (sharp notch) and $0.15 \mathrm{~mm}$ (very sharp notch).

The central part of both lateral and frontal surfaces of the specimens were shot peened to an Almen intensity of $4.5 \mathrm{~N}$ using a $90^{\circ}$ impingement angle with ceramic $\left(\mathrm{ZrO}_{2}\right.$ and $\left.\mathrm{SiO}_{2}\right)$ beads of $60-120 \mu \mathrm{m}$ diameter; details of the experimental setup are presented in [50]. This treatment proved to confer better fatigue performance as compared with samples peened using larger shots $[50,51]$.
Fig. 1 Geometry of specimens with $0.15 \mathrm{~mm}, 0.5 \mathrm{~mm}$ and $2 \mathrm{~mm}$ radii notches. The shot peened area lies between the dashed lines

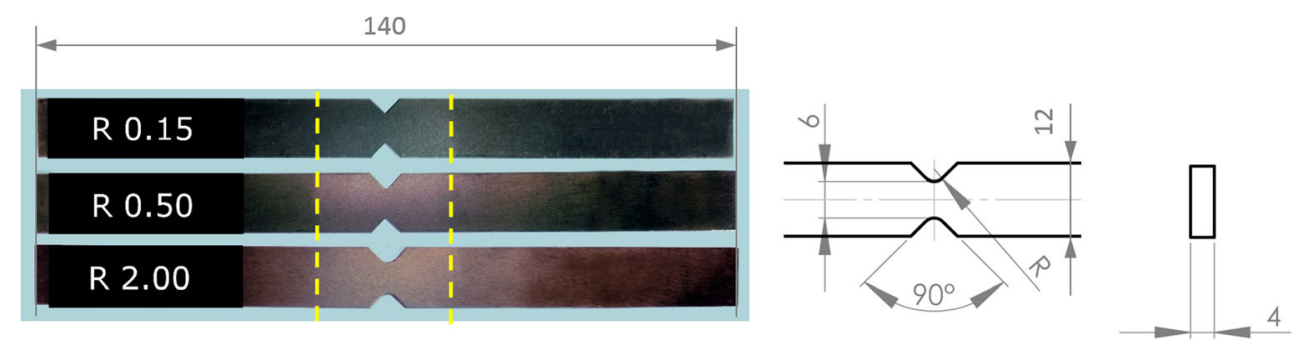


Three sets of XRD measurements were carried out in the centre of the frontal surface of plain samples to investigate the far-field in-depth residual stress profile, as reported in [12] using an AST X-Stress 3000 X-ray diffractometer operated with $\mathrm{Cr} \mathrm{K} \alpha$ radiation. The region of interest was limited by a collimator to $1 \mathrm{~mm}^{2}$ in area. Depth profiling was conducted step-by-step by removing a very thin layer of material $(10,15$, 30,45 and final layer at $55 \mu \mathrm{m}$ below the surface) in a $2 \mathrm{~mm} \times$ $2 \mathrm{~mm}$ region by electropolishing. This experimental setup comply recommendations from standard SAE HS-784, 2003. The classical $\sin ^{2} \psi$ method was applied using of $9 \psi$ angles between -45 and $+45^{\circ}$ for each measurement. The $\langle 311\rangle$ diffracting planes were chosen (i) in order to obtain high angle measurements $\left(2 \theta=139.0^{\circ}\right)$ giving good strain sensitivity, and (ii) because they do not accumulate significant intergranular stresses and hence represent the behavior of the bulk well.

Next, $\mu$ XRD measurements were carried out on notched specimens in order to map the residual stress field in the X-direction in the vicinity of the notch root using a Bruker's D8 Discover XRD2 micro-diffractometer (shown in Fig. 2(a) and (b)) equipped with General Area Diffraction Detection System (GADDS) and Hi-Star 2D area detector. Tube parameters of $40 \mathrm{kV} / 40 \mathrm{~mA}$ using $\mathrm{Cu}-$ $\mathrm{K} \alpha$ radiation at a detector distance of $30 \mathrm{~cm}$ which covers approximately the area of $20^{\circ}$ in $2 \theta$ and $20^{\circ}$ in $\gamma$ with $0.02^{\circ}$ resolution was used. A motorized five axis $(\mathrm{X}, \mathrm{Y}, \mathrm{Z}$ (translation), $\psi$ (tilt), $\varphi$ (rotation)) stage was used giving $12.5 \mu \mathrm{m}$ position accuracy and $5 \mu \mathrm{m}$ repeatability. Initially, we analyzed the RS field in the untreated region and a treated region far from the notch, where lateral RS gradients are expected to be low. For this reason, we used a $800 \mu \mathrm{m}$ pinhole optic to collect two X-ray diffraction patterns, depicted in Fig. 3(a) and (c), for the untreated (shown in Fig. 3(b) and far-field peened (shown in Fig. 3(d) locations, respectively. As illustrated in Fig. 3(e), the compressive RSs shift the detected diffraction rings to lower diffraction angles. The peak shift is more pronounced for $\langle 220\rangle$ and $\langle 311\rangle$ rings, this latter was selected for the subsequent RS measurements to ensure adequate strain sensitivity due to higher angle measurements.

Then the RS field, $\sigma_{x}(y)$, were mapped in the X-direction in the vicinity of the notch root along the bisector connecting the two notch roots (as shown in Fig. 4). To ensure enough lateral resolution, the gauge area was limited using a $50 \mu \mathrm{m}$ pinhole capillary focusing optics. This very small beam size required a long exposure time per frame equal to $1200 \mathrm{~s}$. Tilt angles $\psi$ comprised between -20 and $+50^{\circ}$ were explored to apply the $\sin ^{2} \psi$ method. Two dimensional frame data were imported to Bruker's LEPTOS software for RS evaluation. Each frame was divided to sub regions and locally integrated along the $\gamma$ (azimuthal) direction to obtain 1D diffraction pattern with sufficient counts to determine the $2 \theta$ position from the weak diffraction signals. More details about RS analysis with 2D $\mathrm{XRD}$ can be found in [52]. Correction on polarization, background, $\mathrm{K}_{\alpha 2}$ was performed. The peak positions were determined by fitting Pearson VII type peak. Due to the related large number of points available of a diffraction peak, Pearson VII function is statistically reliable. For the given angular resolution of $0.01^{\circ}$, a residual stress with magnitude of $\pm 1.0 \mathrm{MPa}$ was measured. The surface residual stress profile between the two notches was mapped through 11 measurements spaced $50 \mu \mathrm{m}$ apart starting from the notch tip (Fig. 4). The laser video sample alignment system, depicted in Fig. 2(b), was used to position the specimen with respect to the incident X-ray beam. The Brukers Absorb DX V1.1.4 software was used to calculate the penetration depth of the $\mathrm{X}$-ray beam on the base of the theoretical analysis explained in detail in [52]. It calculated that the $\sim 45 \mu \mathrm{m}$ thick surface layer (viz. the layer interested by compressive RS as shown in the next section) contributes by $90 \%$ to the diffracted beam, while $50 \%$ of the RS information stems from the outer $15 \mu \mathrm{m}$.

After $\mu$ XRD measurement, the longitudinal stress was mapped at the same locations using SEM-FIB Micro-Hole Drilling and Micro-Slot Cutting methods directly on the aspeened surface (Set I) and about $30 \mu \mathrm{m}$ below (Set II) the peened surface after polishing away the top surface (the
Fig. 2 Photograph of the XRD2 micro-diffractometer used to map the residual stress line profile in the notch specimen along the notch bisector. (a) Overview of the instrumentation, (b) detail of the laser video sample alignment system and coordinate system used
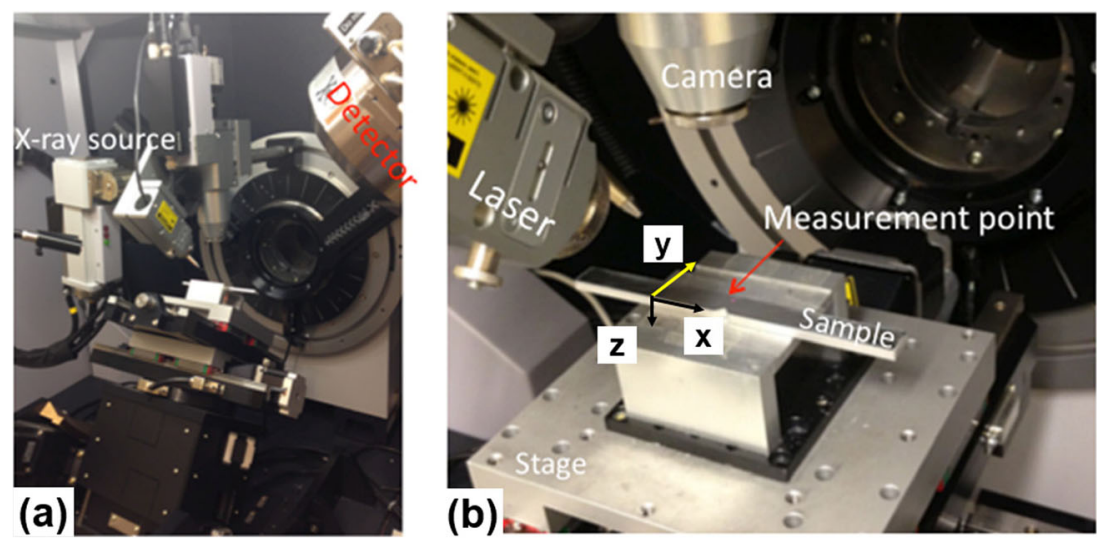
Fig. 3 X-ray diffraction rings of (a) untreated and (c) peened regions. Measurements locations, far from (b) and in the center (d) of the peened region. (e) X-ray diffraction patterns of shot peened and untreated surfaces
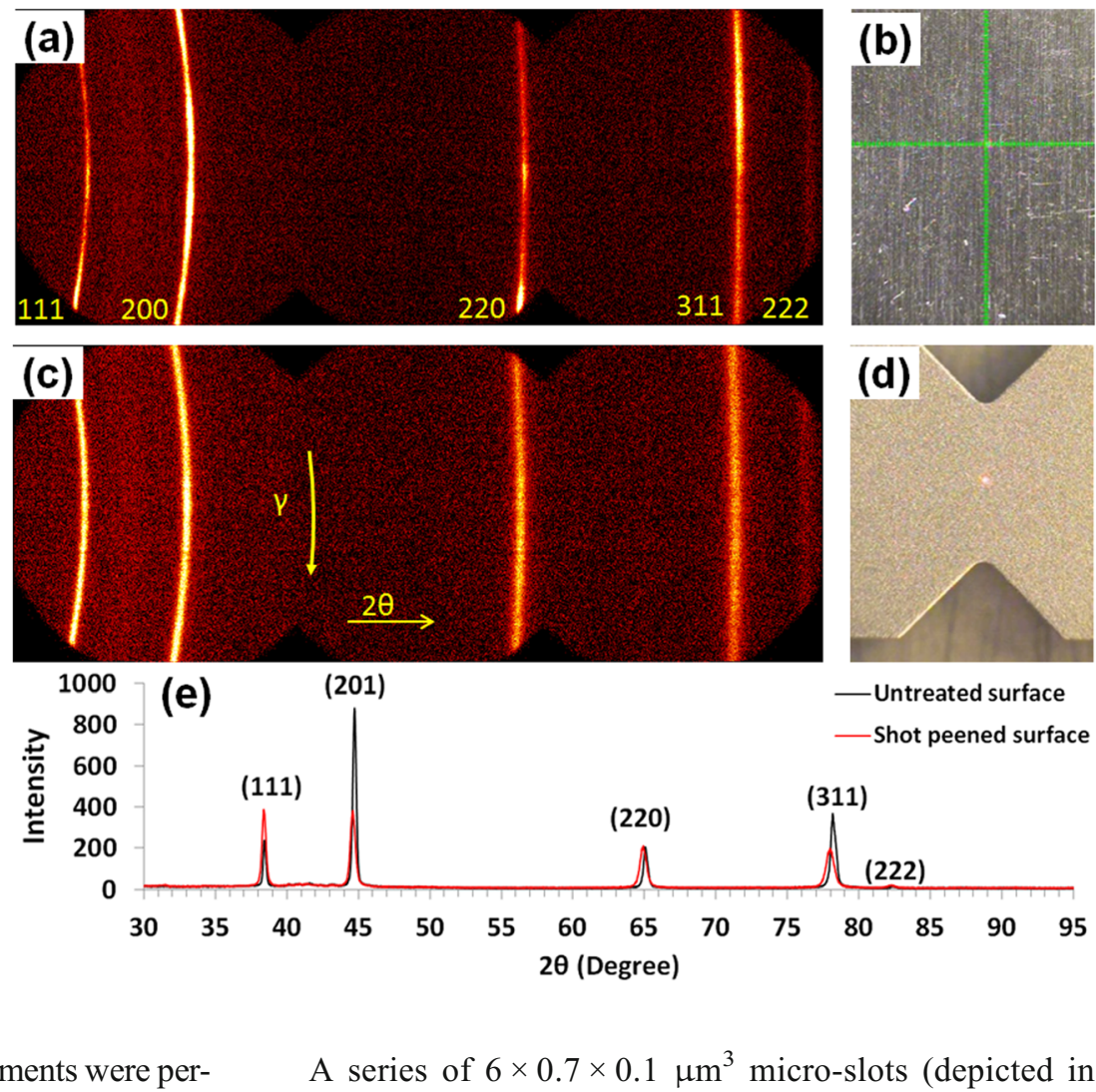

(201)

- Untreated surface

- Shot peened surface

methods are presented below). These measurements were performed using a FEI Nova NanoLab 600i Dualbeam FIB-SEM microscope ${ }^{1}$ with digital image correlation of surface features [53]. Since the RS profile changes with the depth from the surface (as discussed in the next section), the Set II measurements are designed to sample at the same depth as that probed by $\mu \mathrm{XRD}$. This is important because the slotting and hole drilling measurements sample much smaller gauge volumes than XRD $\left(\mu \mathrm{HD}: 5 \times 5 \times 0.5 \mu^{3}\right.$ [54] and $\mu$ SC $30 \times 30 \times$ $5 \mu^{3}$ [43] compared with $50 \times 50 \times 40 \mu \mathrm{m}$ for $\mu \mathrm{XRD}$ in the current study).

In order to reduce the rate of re-deposition of the excavated material, to improve the topographic contrast and prevent overexposure to $\mathrm{Ga}^{+}[42,43,53]$ when FIB milling we used a Gatan PECS 682 etching-coating system equipped with a Gatan 681.20000 thickness metre to sputter a $\sim 10$ nm-thick carbon film on the specimen surface prior to FEGSEM imaging and FIB milling. The carbon target was exposed to a broad argon-ion beam of the current of $550 \mu \mathrm{A}$ accelerated with the electric potential of $10 \mathrm{kV}$ in a vacuum environment of $\sim 2 \times$ $10^{-5}$ Torr.

Next platinum (Pt) nano-dots (diameter $\sim 20-40 \mathrm{~nm}$ ) were laid down by e-beam assisted deposition from gaseous precursor as illustrated in Figs. 5 and 6. The Pt nano-dots enhance the topological contrast of FEGSEM imaging and improve the accuracy of DIC displacement/strain measurement [53].

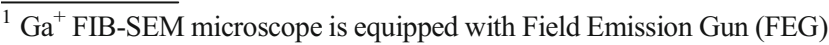
electron column.
}

A series of $6 \times 0.7 \times 0.1 \mu^{3}$ micro-slots (depicted in Fig. 5(b)) and then $1 \mu \mathrm{m}$ diameter by $0.8 \mu \mathrm{m}$ deep microholes of (depicted in Fig. 6(b)), spaced about 4-5 times the slot length, were milled (48 pA at $30 \mathrm{kV}$ ) along the notch bisector near the notch root (as shown in Fig. 4). The dimensions of the holes and slots were selected so, that the gauge volumes are similar and equal about $10 \times 10 \times 0.7 \mu \mathrm{m}^{3}$. In the stress mapping process a sequence of three FEGSEM images (image size $1024 \times 943$ pixels, dwell time, $D_{t}=3 \mu \mathrm{s}, 8$ frames averaged, ETD detector) of the patterned areas were acquired at $0^{\circ}$ stage tilt before (Figs. 5(a) and 6(a)) and three images after milling (Figs. 5(b) and 6(b)).

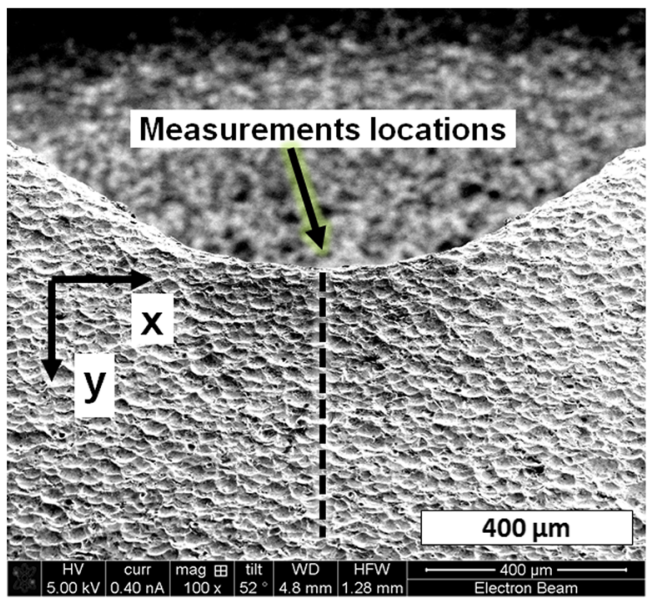

Fig. 4 FEGSEM image is showing the measurements locations 

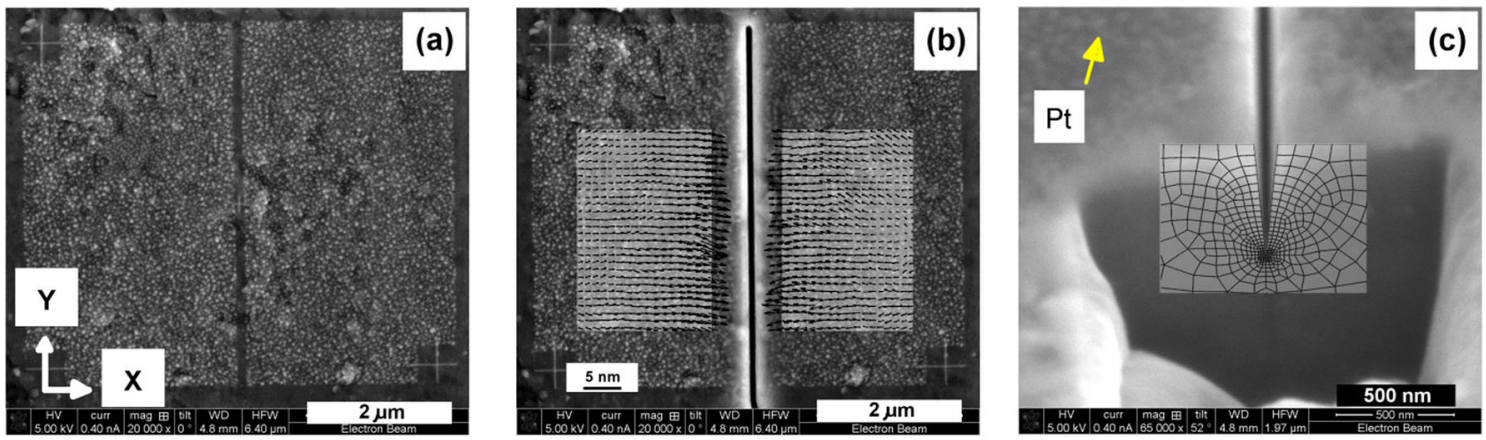

Fig. 5 FEGSEM images show patterned area before (a) and after (b) micro-slotting together with locations of DIC measured displacements (vector lengths are exaggerated; scale bar shows $5 \mathrm{~nm}$ length). The slot size is $6 \times 0.7 \times 0.1 \mu \mathrm{m}^{3}$. The actual slot depth is measured from an end trench FIBed after slotting (c). This image shows superimposed FEA model of a micro-slot used in stress calculations

In contrast to the traditional strain gauge style measurements, $\mu \mathrm{SC}$ and $\mu \mathrm{HD}$ techniques measures surface displacements, not strain. Estimation of surface strains from displacement measurements involves numerical differentiation, which an inherently noisy process, and so is to be avoided. Thus, it is desirable to work directly with displacement data. Surface displacements due to the stress relaxation were measured for each micro-slot and micro-hole by DIC analysis [44], LaVison DaVis 7.2 software. During the analysis, images are divided into smaller sub-regions (patches), which are individually correlated. We only analyze displacements within a certain region: (a) for $\mu \mathrm{SC}$ an average displacement normal to the slot face in a region defined by the highlighted rectangular areas in Fig. 5(b), as experimentally and numerically verified in [43]; (b) for $\mu \mathrm{HD}$ in the region between the inner and outer radius in Fig. 6(b), as experimentally verified in [41]. In both cases we use confined areas because the displacements are too small further from the slot $(x / a>4$; $a$ is the slot depth) and the hole $\left(r_{2} / r_{0}>2.5 ; r_{0}\right.$ is the hole radius, $r_{2}$ is the outer radius $)$, and because redeposition of excavated material can give rise to errors closer to the slot $(x / a<0.8)$ and the hole $\left(r_{1} / r_{0}<1.4\right.$; $r_{l}$ is the outer radius).

For an infinitely long narrow slot the surface displacements near the slot and normal to the crack faces, $U_{x}$, are given by a closed form solution (the Inglis-Muskhelishvili solution) [55]:

$U_{x}=\frac{2.243}{E^{\prime}} \sigma_{x} \int_{0}^{a} \cos \theta\left(1+\frac{\sin ^{2} \theta}{2(1-\nu)}\right)(1.12+0.18 \cdot \operatorname{sech}(\tan \theta)) d a$

where $\theta=\arctan (x / a), a$ is the slot depth, $x$ is the distance from the slot, $E^{\prime}=E /\left(1-\nu^{2}\right), \nu$ is the Poisson ratio and $\sigma_{x}$ is the residual stress. From this it can be seen that the displacements normal to the crack faces along the $x$ direction are not affected by the stress $\sigma_{y}$ (acting parallel to the crack) [56]. In our case the sample is represented by a linear-elastic-isotropic material: $E=73 \mathrm{GPa}$, and $v=0.33$ [50]. Assumption of isotropic material is valid since the elastic anisotropy of Al-alloys is low, described by the
Zener coefficient of $A_{z}=1.2 .^{2}$ This has negligible effect on residual stress estimates [54]. Since focused ion beam milling does not produce ideal straight sided infinitely long slots, FE analysis (Simuila Abaqus 6.14-2) has been used to evaluate reference surface displacements, $U_{x}$. Details of FE analysis are presented elsewhere [43]. In order to determine the stress from the displacements measured by DIC, the measured average displacements, $u_{x}$, at each measurement location on either side of the slot, $x / a$, are plotted against the displacements expected for a -1GPa uniaxial stress, $U_{x}$, calculated above (in our case using the 2D wedge-slot FE analysis shown in Fig. 5(c)) and a line of best fit plotted. Assuming totally elastic accommodation, the gradient of the best-fit line, $m$, is equal to the best-fit stress in GPa. The uncertainty of stress measurements are calculated from $95 \%$ confidence level of the linear fit.

The radial displacements, $\delta(r, \theta)$, of the surface around a circular hole drilled in a uniformly stressed material with dimensions much greater than the hole size have a trigonometric form [41]:

$\delta_{r}(r, \theta) a^{-1}=\left[P u_{r}(r, \theta)+Q \nu_{r}(r, \theta) \cos 2 \theta+T \nu_{r}(r, \theta) \sin 2 \theta\right] E^{-1}$

where the stresses

$P=\left(\sigma_{x}+\sigma_{y}\right) 2^{-1} \quad Q=\left(\sigma_{x}-\sigma_{y}\right) 2^{-1} \quad T=\tau_{x y}$

respectively represent the isotropic stress, the $45^{\circ}$ shear stress, and the axial shear stress. In equation (2), $u_{r}(r, \theta)$ is the radial profile of the radial displacements caused by a unit isotropic stress $P$, and $v_{r}(r, \theta)$ is the radial profile of the radial displacements caused by unit shear stresses $Q$ or $T$.

The corresponding circumferential displacements have a following form:

$\delta_{r}(r, \theta) a^{-1}=\left[Q v_{\theta}(r, \theta) \cos 2 \theta+T \nu_{\theta}(r, \theta) \sin 2 \theta\right] E^{-1}$

\footnotetext{
${ }^{2} \mathrm{~A}_{\mathrm{z}}=2 \mathrm{c}_{44} /\left(\mathrm{c}_{11}-\mathrm{c}_{12}\right)$ where $\mathrm{c}_{\mathrm{xx}}$ are elastic stiffnesses (for $\mathrm{Al}$ : $\mathrm{c}_{11}=108.0 \mathrm{GPa}, \mathrm{c}_{12}=61.2 \mathrm{GPa}$ and $\left.\mathrm{c}_{44}=28.6 \mathrm{GPa}\right)$
} 

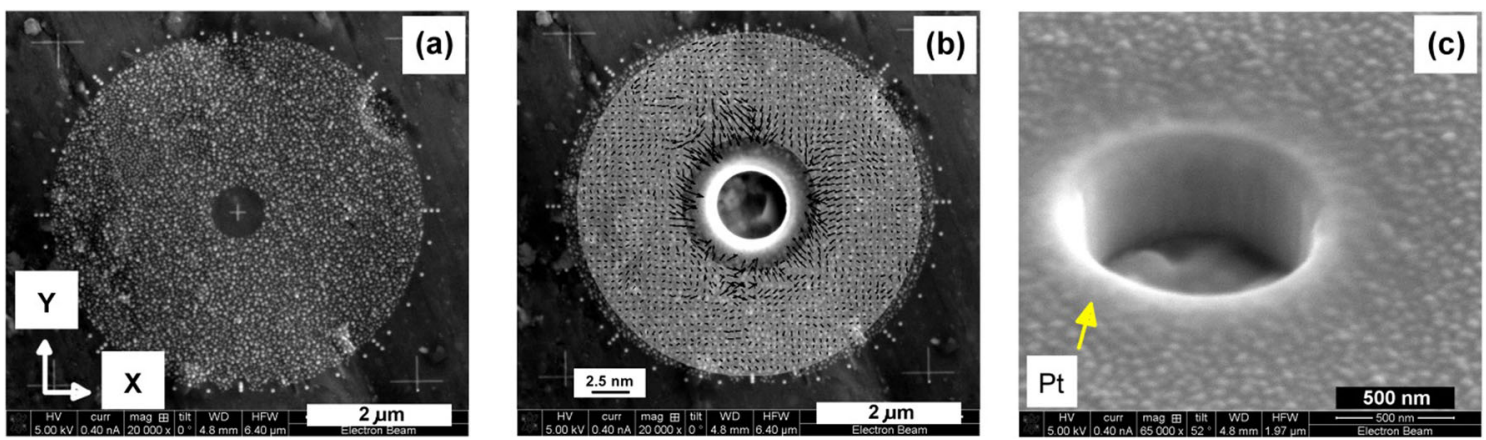

Fig. 6 FEGSEM images show patterned area before (a) and after (b) micro-hole milling together with locations of DIC measured displacements (vector lengths are exaggerated; scale bar shows $2.5 \mathrm{~nm}$ length). The hole is $1 \mu \mathrm{m}$ diameter and $0.8 \mu \mathrm{m}$ deep as measured from SEM image taken at oblique angle (c)

where $v_{\theta}(r, \theta)$ is the radial profile of the circumferential displacements caused by unit shear stresses $\mathrm{Q}$ or $\mathrm{T}$.

The normalizations by hole radius $a$ and Young's modulus $E$ non-dimensionalizes the radial displacement profiles $u_{r}(r, \theta)$ and $v_{r}(r, \theta)$. The resulting numerical values depend on hole depth and can be computed using finite element analysis [44]. Since DIC measurements are scale independent, it is convenient to measure the displacements $\delta_{r}(r, \theta), \delta_{\theta}(r, \theta)$ and hole radius a in units of image pixels.

After some mathematical rearrangements and adding correction for SEM image stretch and shear artefacts equation (1) can be expressed in compact $9 \times 9$ matrix form (see the derivation of formula in [41])

$\overline{\boldsymbol{G}}^{\boldsymbol{T}} \overline{\boldsymbol{G}} \overline{\boldsymbol{w}}=\overline{\boldsymbol{G}}^{\boldsymbol{T}} \bar{\delta}$

Where $\overline{\boldsymbol{G}}$ is a matrix of the radial profile of the radial displacements caused by a unit stresses $P, Q$ and $T ; \overline{\boldsymbol{G}}$ has $2 \mathrm{~N}$ rows, 9 columns and $\mathrm{N}$ is the number of pixel of image used for DIC calculations; $\overline{\boldsymbol{w}}$ encapsules correction for SEM image stretch and shear artefacts; $\overline{\boldsymbol{G}}^{\boldsymbol{T}} \overline{\boldsymbol{\delta}}(1 \times 9$ vector $)$ accumulates various of the products of the matrix coefficients and displacements at each pixel used for DIC calculations. Three images collected before and three after micro-hole milling allows averaging measured stress components $\left(\sigma_{x}, \sigma_{y}, \tau_{x y}\right)$ from $9^{3}$ data points. The uncertainty of measurements of the three stress components is equal to standard deviation of 9 measured data points for each micro-hole.

After milling each slot, an end trench is milled at $52^{\circ}$ stage tilt in order to monitor the depth and shape of each FIBprocessed slot (Fig. 5(c)), whereas the actual hole depths were measured from FEGSEM directly after hole milling (Fig. 6(c)). Monitoring the depth is important because it is not possible to excavate deep micro-slots having perfectly rectangular walls,

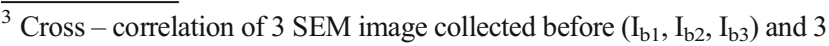
after $\left(\mathrm{I}_{\mathrm{a} 1}, \mathrm{I}_{\mathrm{a} 2}, \mathrm{I}_{\mathrm{a} 3}\right)$ micro-hole drilling allows calculate $9\left(\mathrm{I}_{\mathrm{b} 1}-\mathrm{I}_{\mathrm{a} 1}, \mathrm{I}_{\mathrm{b} 1}-\mathrm{I}_{\mathrm{a} 2}\right.$, $I_{b 1}-I_{a 3}, I_{b 2}-I_{a 1}, I_{b 2}-I_{a 2}$, etc.) displacement field maps later used for the residual stress calculation.
}

and the predefined slot depth may vary substantially from the actual depth since the FIB milling rate depends both on the material milled and its crystallographic orientation [57]. Later FEGSEM images and the actual shapes of slot and holes were used in the automated stress calculation algorithms for the $\mu \mathrm{SC}$ $[43,45]$ and $\mu \mathrm{HD}[42,44]$ methods.

After the measurements on the top surface (Set I), material was very gently removed to a depth of $30 \mu \mathrm{m}$ using sand papers $(800,1200,2500)$, aqueous silica suspensions $(9,6,3,1$, $0.25 \mu \mathrm{m})$ and finally $0.05 \mu \mathrm{m}$ colloidal silica. Then the samples were cleaned in ethanol and after drying the samples were carbon coated and the $\mu \mathrm{HD}$ and $\mu \mathrm{SC}$ measurements were repeated at the same locations (Set II). These measurements rely on the assumption that the gentle mechanical removal of a tiny surface layer does not significantly affect the RS distribution. This has been experimentally validated in [12], where similar shot peened samples were tribofinished to remove a material surface layer of $5 \div 10 \mu \mathrm{m}$ thickness from the entire frontal surface. XRD measurements on the tribofinished surface revealed that the material removal exposes on the surface the RS that was present at the corresponding depth prior to polishing. This observation is consistent with the experimental analyses made in [21], where the indepth RS profile of shot peened samples was measured both nondestructively through neutron diffraction and destructively using laboratory incremental layer removal XRD, showing very similar trends, even at depths of $200 \mu \mathrm{m}$ and more.

To reveal the 3D microstructural details of the surface layers modified by the SP treatment, i.e. grains, networks of sub-surface cracks, intermetallics voids, etc., and link them to the RS measurements undertaken on the surface and depth profiled with micromechanical and X-Ray diffraction methods, we used FEI Helios Plasma $\mathrm{Xe}^{+}$Focused Ion Beam - Scanning Electron Microscope ${ }^{4}$ (PFIB-SEM) for serial sectioning tomography technique (SST). PFIB-SEM allows for milling much larger volumes $\left(>100^{3} \mu^{3}\right)$ than $\mathrm{Ga}^{+}$based dual beams, thus within serial sectioned material

\footnotetext{
${ }^{4} \mathrm{Xe}^{+}$PFIB-SEM microscope is equipped with Field Emission Gun (FEG) electron column.
} 
Fig. 7 Depth profile of residual stress, $\sigma_{\mathrm{x}}$, in bead-peened Al7075-T651 measured by AST XStress $3000 \mathrm{X}$-ray diffractometer [12]. Note: Residual stresses are measured on $\mathrm{x}-\mathrm{y}$ plane in

Figs. 2(b) and 4

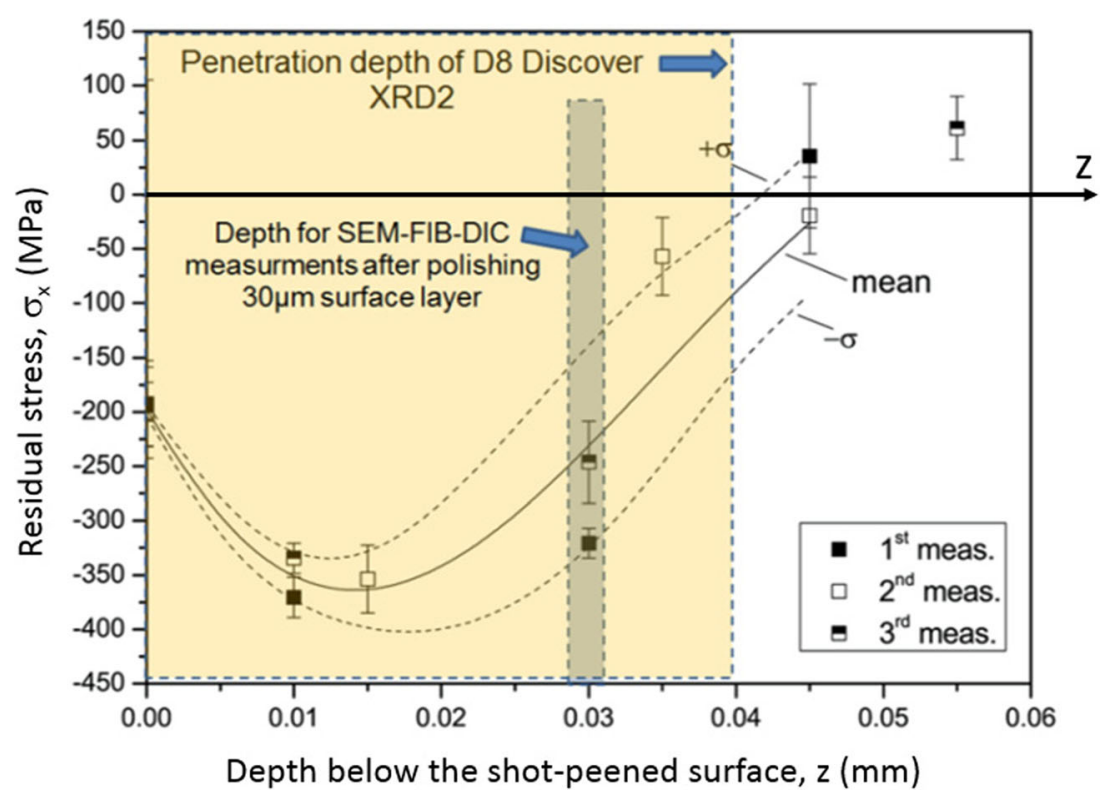

volume we were able to enclose from shot peened sub-micron size grains regions down to the based material. A new version (1.6) of the FEI Slice and View ${ }^{\mathrm{TM}}$ software which incorporates a rocking polish (described in details in [58]) into an automated routine was used for the SST. A block of $100 \times 66 \times 30 \mu^{3}$ on the shot peneed surface of sample with $2 \mathrm{~mm}$ radius notch was sectioned. 300 slices were cut using PFIB at $59 \mathrm{nA}$ current accelerated at $30 \mathrm{kV}$. Each $100 \mathrm{~nm}$ thick slice was cut within $59 \mathrm{~s}$ where the milling depth for the depth of cleaning crosssection (CCS) was set to $80 \mu \mathrm{m}$ using the rocking polish at $\pm 4^{\circ}$ determined experimentally before the actual data collection. Furthermore in the automated procedure for PFIB imaging we used $4096 \times 3536$ pix $^{2}$ and $D_{t}$ of 300 ns. $6144 \times 4096$ pix $^{2}$ FEGSEM images (the resolution of $16 \mathrm{~nm} /$ pixel) were collected using $2 \mathrm{kV} / 2.8 \mathrm{nA}$ and through-lens detector (TLD) having suction tube $(\mathrm{SC})$ voltage $=+244.7 \mathrm{~V}$ and mirror $(\mathrm{M})$ voltage $=$ $+10 \mathrm{~V}$. These images were collected with $D_{t}=3 \mu$ s and a single frame acquisition taking 80 s per image. Overall it took about $15 \mathrm{~h}$ to acquire the whole data set.

Subsequently, to map distribution of elements in the near surface regions we done Energy Dispersive Spectrum (EDS) analysis using FEI Helios PFIB-SEM and Oxford Instruments Silicon Drift Detector 150 X-MaxN and Oxford Aztec 3.0 analysis software. For EDS map on FIB cross-section with high resolution we used low energy mapping at $5 \mathrm{kV}$ and $2.8 \mathrm{nA}$, whereas EDS maps on PFIB cross-section after SST we used broader energy spectrum at $10 \mathrm{kV}$ and $2.8 \mathrm{nA}$. Phases were identified using EDS signal obtained with $10 \mathrm{kV}, 15 \mathrm{kV}$ and $2.8 \mathrm{nA}$ electron beam.

The grains size of the shot peened layers we measured from EBSD map obtained from $\mathrm{Ga}^{+}$FIB milled cross-section (30 kV at $6.5 \mathrm{nA}$ ). We used Oxford Instruments Nordlys Max EBSD Camera attached to FEI Nova NanoLab 600i, Aztec 3.0 suite, and Channel 5 software. We set following experimental conditions: SEM $20 \mathrm{kV}$ at $2.4 \mathrm{nA}$; working distance of $10 \mathrm{~mm}$; the step size of $40 \mathrm{~nm}$; exposure time of $32 \mathrm{~ms}$; 3 frames with binning $4 \times 4$; gain 6; 300 frames for static auto background; optimized indexing mode with edge detection using 10 bands and 70 Hough transform.

Finally $3 \mathrm{D}$ visualization of the serial section data was conducted using FEI - Avizo 9.0.0 software. The stacks of SEM images were aligned using the align slices module
Fig. 8 FEGSEM images shows the location of the set I microslots $\left(6 \times 0.7 \times 0.1 \mu^{3}\right)$ yellow arrows $)$ and micro-holes $(1 \mu \mathrm{m}$ diameter and $0.8 \mu \mathrm{m}$ deep) (white arrows) introduced at the bottom of peening dimples: (a) in the same dimple, (b) in adjacent dimples. Note end trenches milled for each slot. Chequered arrows indicate surface cracks
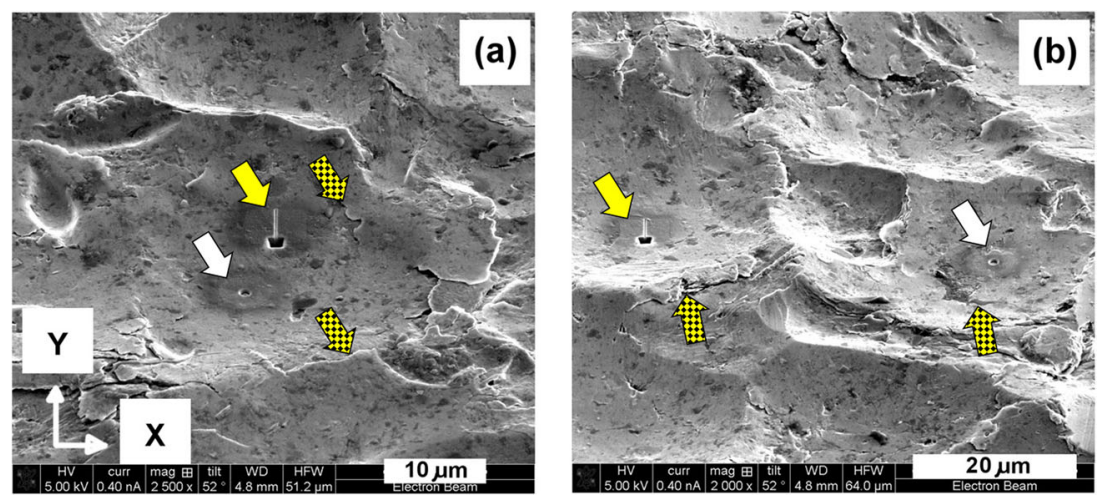
using a least squares algorithm. The aligned images were filtered using the Fourier Filter (FFT Filter), which removes periodic noise such as the vertical curtaining effects produced from the Plasma FIB milling process. FFT filter was used at two angles that match the rocking mill angles. A sharpening filter was subsequently applied to compensate for some blurring resulting from the FFT filter. An edge preserving filter and a median filter were then applied to improve the definition of the cracks and inclusions. The data was then segmented using a semiautomated approach which combined watershed segmentation routine to label the crack regions. This segmentation procedure is incorporated into FEI - Avizo 9.0.0 software.

\section{Results and Discussion}

\subsection{Shot Peening Residual Stresses osn Plain Sample}

The longitudinal residual stress $\left(\sigma_{\mathrm{x}}\right)$ variation with the depth from the bead-peened surface measured by AST X-Stress $3000 \mathrm{X}$-ray diffractometer has the characteristic peened profile with a peak compressive stress $(\sim 350 \mathrm{MPa})$ at a depth about $15 \mu \mathrm{m}$ (in Fig. 7).
Of course the residual stress measured by XRD is an average over the penetration depth weight towards the surface. A best estimate of the profile could be recovered using deconvolution methods similar to those used in $[49,59]$. However, given that the peak stress is broad and centred around $15 \mu \mathrm{m}$ depth, it is likely that the RS determined by micromilling at a depth of $30 \mu \mathrm{m}$ would be expected to be around $250 \mathrm{MPa}$.

\subsection{Surface Residual Stress Measurement Between the Notches}

While ceramic bead-peened surfaces are typically much smoother than metal shot peened ones [50], these surfaces are very rough at the $50 \mu \mathrm{m}$ level showing a pattern of overlapping dimples (see Fig. 8(a) and (b)). The surface roughness determines the locations where micron-size slots/holes can be introduced. In this case, micro-slots and micro-holes were introduced at the bottom of concave dimples, as shown in Fig. 8(a), spaced apart at least 4-5 times the slot length. In several locations the dimples were too small to accommodate two measurement points, thus these were milled in the adjacent dimples (see Fig. 8(b)).

Inspections of the surface also reveal a network of surface cracks (chequered arrows in Figs 8, 9(a,b) and 10) that span
Fig. 9 (a) FEGSEM image $(5 \mathrm{kV} / 400 \mathrm{pA}$, ETD detector) is showing surface cracks and position of FIB cross-section (b) view of a FIB cross-section revealing sub-surface damage and intermetallic phases; (c) show EDS maps of elements taken at $5 \mathrm{kV} / 2.8 \mathrm{nA}$
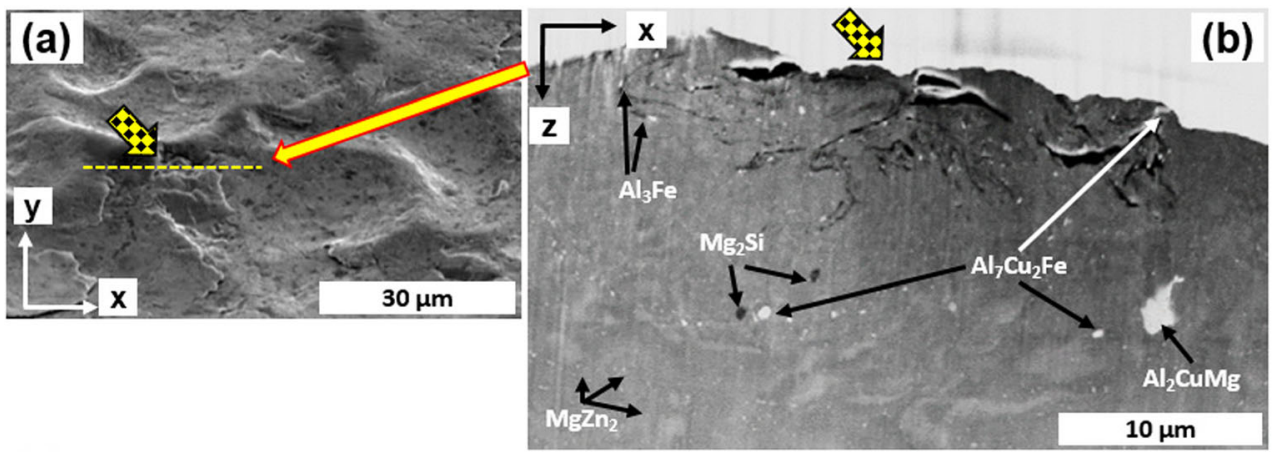

(c)

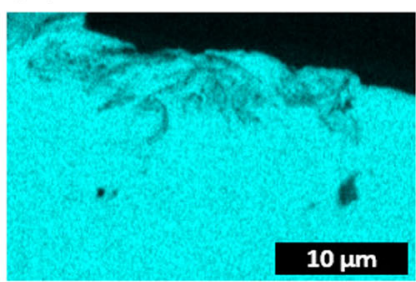

$\mathrm{O} K \alpha 1$

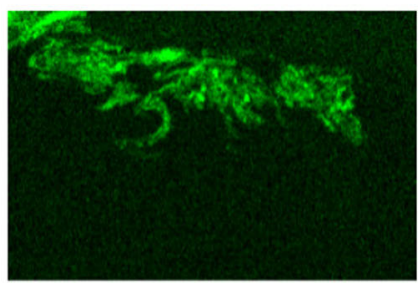

Si $K \propto 1$

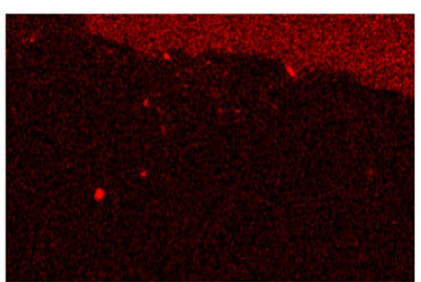

Fe L $\alpha 1 \_2$

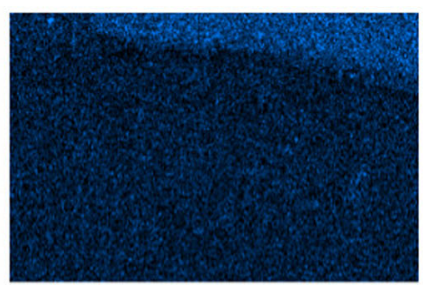

$M g$ Ka1_2

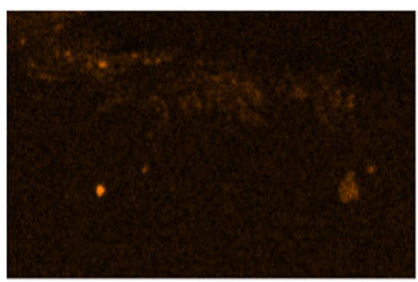

Cu L $\alpha 1 \_2$

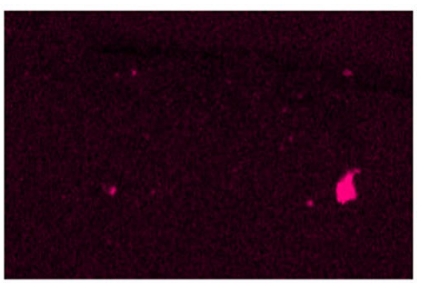


Fig. 10 (a) FEGSEM image $(5 \mathrm{kV} / 2.8 \mathrm{nA}$, ETD detector) is showing surface cracks, 1 and 2 , and area from where SST data was collected (b) show reconstructed SST volume of size of $100 \times 60 \times 30 \mu^{3}$, where external surface of the volume are displayed; top surface is shown about $300 \mathrm{~nm}$ below the peened surface to expose the network of cracks (1 and 2) and highly deformed near surface regions; (c) shows volume rendering of reconstructed cracks in the network (1); (d) top surface on the right hand side of the dashed yellow line is shown about $3 \mu \mathrm{m}$ below the peened surface to expose reconstructed the network of cracks (2) and highly deformed near surface regions;. (e) shows cross-section of the

microstructure with reconstructed cracks in the network (1) together with superimposed mean residual stress profiles taken from Fig. 7; Note: FEGSEM images in (b)-(e) were collected using $2 \mathrm{kV} / 2.8 \mathrm{nA}$ and TLD detector
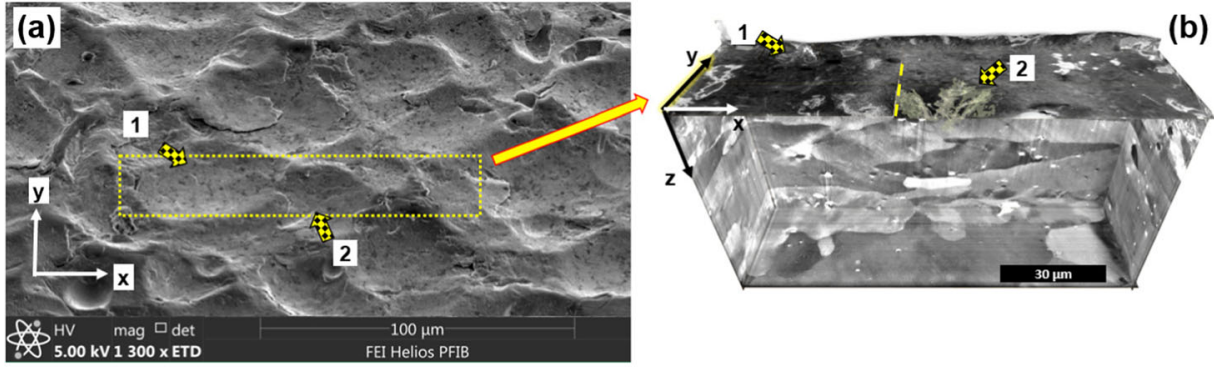

(c)
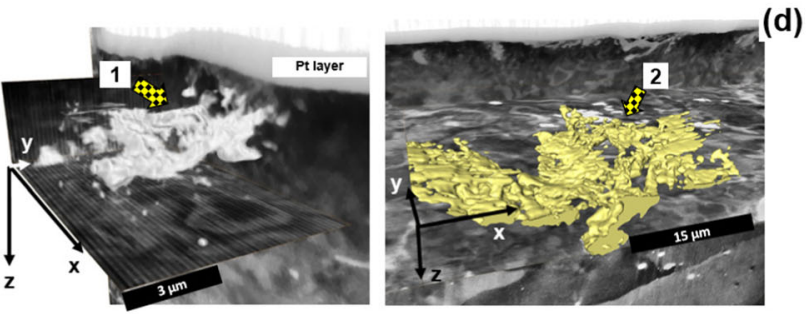

(e)

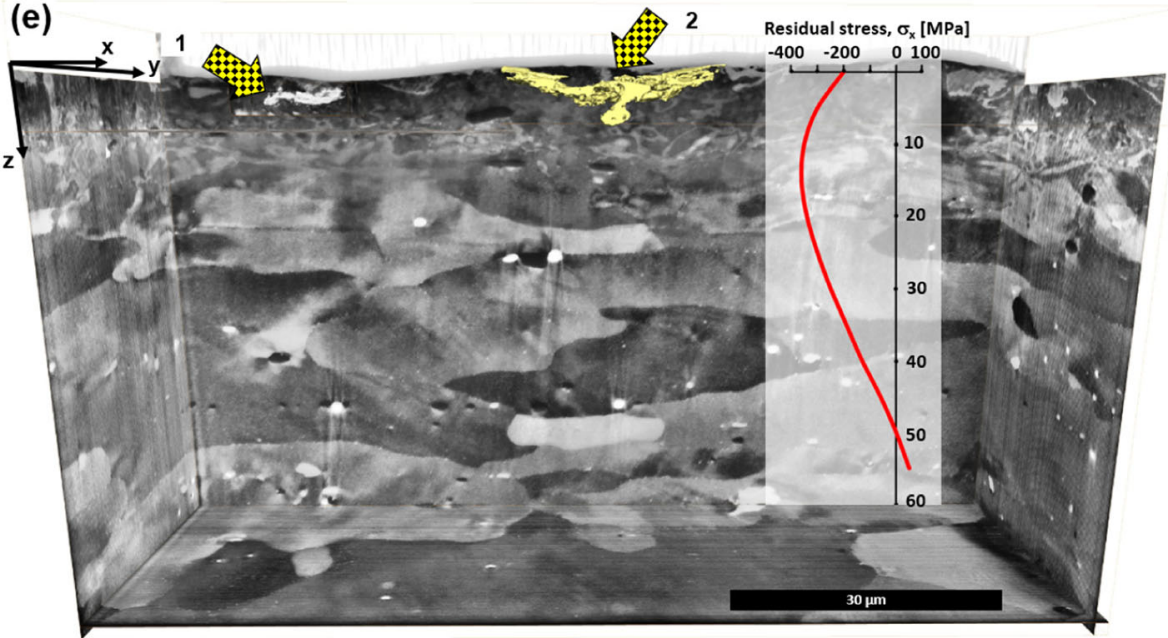

under the surface down to about 3-8 $\mu \mathrm{m}$. Sub-surface investigation in 3D by PFIB-SEM SST (in Fig. 9) in the vicinity of the cracks clearly shows that cracks propagate and branch below the surface to a depth of at least $3 \mu \mathrm{m}$ where distinctive material deformation patterns are observed; as illustrated in Figs. 9(b) and 10(e). Multiple voids of size of hundreds of $\mathrm{nm}$ and various phases $\left(\mathrm{MgZn}_{2}, \mathrm{Mg}_{2} \mathrm{Si}, \mathrm{Al}_{3} \mathrm{Fe}, \mathrm{Al}_{7} \mathrm{Cu}_{2} \mathrm{Fe}\right.$ and $\mathrm{Al}_{2} \mathrm{CuMg}$ eutectic phase precipitates) are observed as well; depicted in Figs. 9(b) and 11(a). Cracked and highly deformed surface regions contain measurable amount of oxygen indicating existence of fine aluminium oxide bands formed along crack faces. In the surface region embedded $\mathrm{SiO}_{2}$ was found originated from the ceramic beads used for shot peening.

Electron channeling FEGSEM images (Figs. 10(b-e) and 11(a)) and EBSD maps (Fig. 11(b)) revealed that highly plastically deformed sub-surface regions reaches to depths of $30 \mu \mathrm{m}$ indicating that the plastically affected material volumes exist below $30 \mu \mathrm{m}$ depth. Indeed, there is very good correlation between residual stress depth profile (Fig. 10(e)) and microstructural features captured by electron channeling imaging combined with large volume SST 3D visualization and EBSD maps. Surface layers a few microns deep are highly plastically deformed with a sub-micrometer size grains ${ }^{5}$ (Fig. 11(b)) and a network of sub-surface cracks, which releases residual stresses and the drop of compressive stresses is observed, in Figs. 7 and 10(e). At shallow depths above $10 \mu \mathrm{m}$ the plastic deformation is still very high, but the cracks are not present, this allows for reaching the highest compressive residual stresses (the depth of $\sim 15 \mu \mathrm{m}$ ). Since the most of kinetic energy of beads is absorbed by the surface layers, the compressive RSs are reduced with depth. This is reflected by larger grains with lower electron channeling contrast (at depth $>30 \mu \mathrm{m}$ in Figs. 10(e) and 11(a) and (b)).

Figure 12 compares the stresses measured at the surface by mechanical methods with those measured by $\mu$ XRD for three

\footnotetext{
${ }^{5}$ The average grain size, described as equivalent circle diameter, is $0.95 \mu \mathrm{m}$ as measured from the top surface down to $10 \mu \mathrm{m}$ below the SP surface.
} 
Fig. 11 (a) FEGSEM image $(2 \mathrm{kV} / 2.8 \mathrm{nA}$ and TLD detector) is showing the last slice of the SST data set with identified phases; (b) EBSD maps (Inverse Pole Figure and Band Contrast) collected on a cross-section near shot-peened region; (c) shows EDS maps of elements taken at $10 \mathrm{kV} / 2.8 \mathrm{nA}$
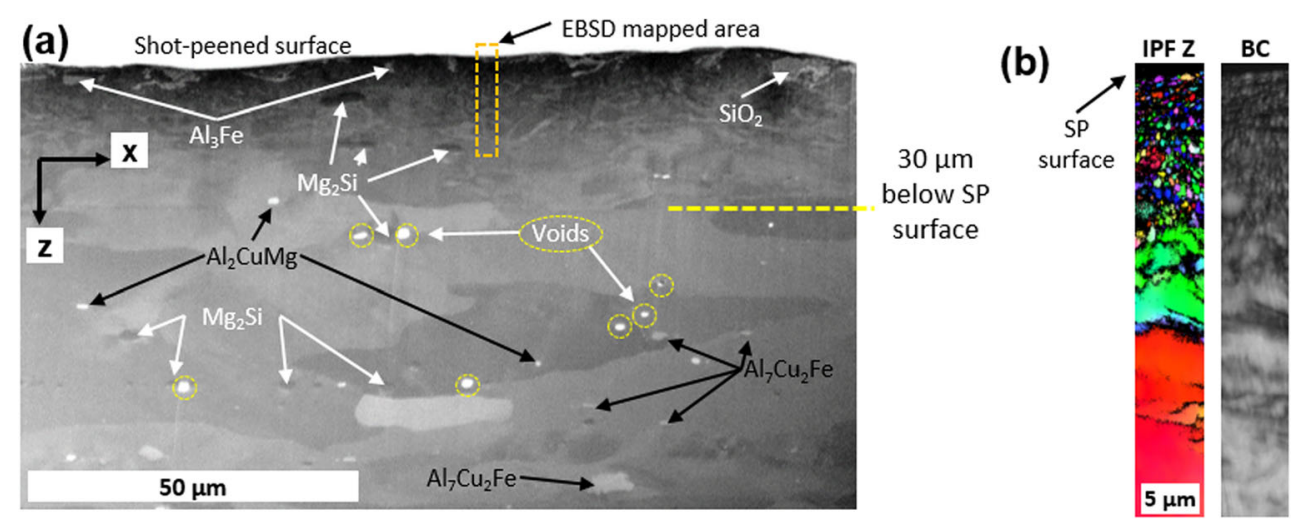

(c)

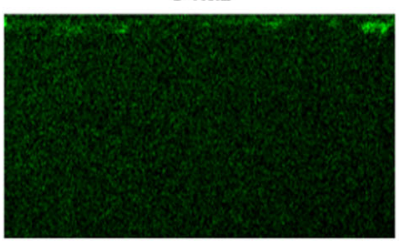

Si K $\alpha 1$

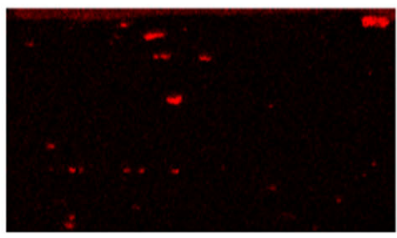

Al K $\alpha 1$

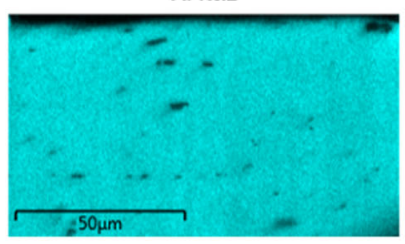

Cu Ka1

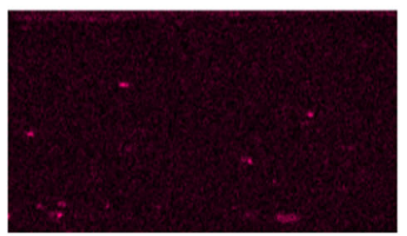

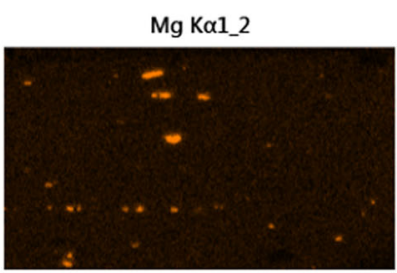

Fe K $\alpha \mathbf{1}$

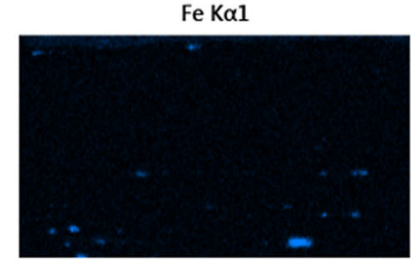

samples having notch radii of $0.15 \mathrm{~mm}, 0.50 \mathrm{~mm}$ and $2 \mathrm{~mm}$. The detailed analyses of the role of the RS field ahead of the notch root is beyond of the scope of this paper and can be found in the companion paper [49] and elsewhere [7]. The $\mu \mathrm{XRD}$ profile which samples over a larger depth and a wider area laterally is much smoother as one would expect. In this case local variations of residual stresses caused by microstructural imperfections are averaged. The micro-milling methods display large lateral point-to-point variations in the RS which in view of the point-to-point variations in the deformation, near surface damaged topography (Figs. 9 and 10) and the very high level of surface specificity $(<1 \mu \mathrm{m})$ of the techniques is perhaps not surprising. Indeed the micron sized footprints of the slots and holes have enabled a measure the heterogeneity in residual stress $(\sim+/-150 \mathrm{MPa})$ at the surface to be quantified for the first time.

Shot peening conducted at low intensities with small beads is more effective in incrementing the fatigue resistance as compared to more intense treatments with larger shots [12], since it causes a lower surface roughening and induces the maximum compressive residual stress as close as possible to the surface. However current study shows that in the superficial surface layer tensile residual stresses are present (Fig. 12) and fine sub-surface crack networks exist and can act as the nuclei for the fatigue cracks.

\subsection{Sub-Surface Residual Stress Measurement Between the Notches}

Given the microstructure of the dimples one would expect the microstresses to decay quickly by St Venant's principle with distance from the surface to give the long range stress field typically sampled by XRD. We found that by very gentle and multiple step mechanical polishing to a depth of $\sim 30 \mu \mathrm{m}$ it was possible to remove the highly deformed and defective layer to obtain a smooth surface (Fig. 13(a)). Figures 10(e), 11(a) and FEGSEM images of a FIB milling cross-section (Fig. 13(b)) reveals little evidence of damage of severe plasticity with uniformly distributed various of precipitates and large aluminium grains. Additionally Fig. 13(b) confirms that the very gentle mechanical removal methodology used for polishing was correctly applied, since electron channeling contrast SEM image (in Fig. 13(b)) shows consistent variation of gray-level contrast associated with the shot peening.

The RS profiles measured by the micro mechanical relaxation methods at $30 \mu \mathrm{m}$ below the peened layer are presented in Fig. 14. As one might expect the micromechanical relaxation methods give stress profiles that are now much smoother than in Fig. 12. Furthermore they are in good agreement with the $\mu$ XRD measurements, which are representative of a similar depth. The scatter 

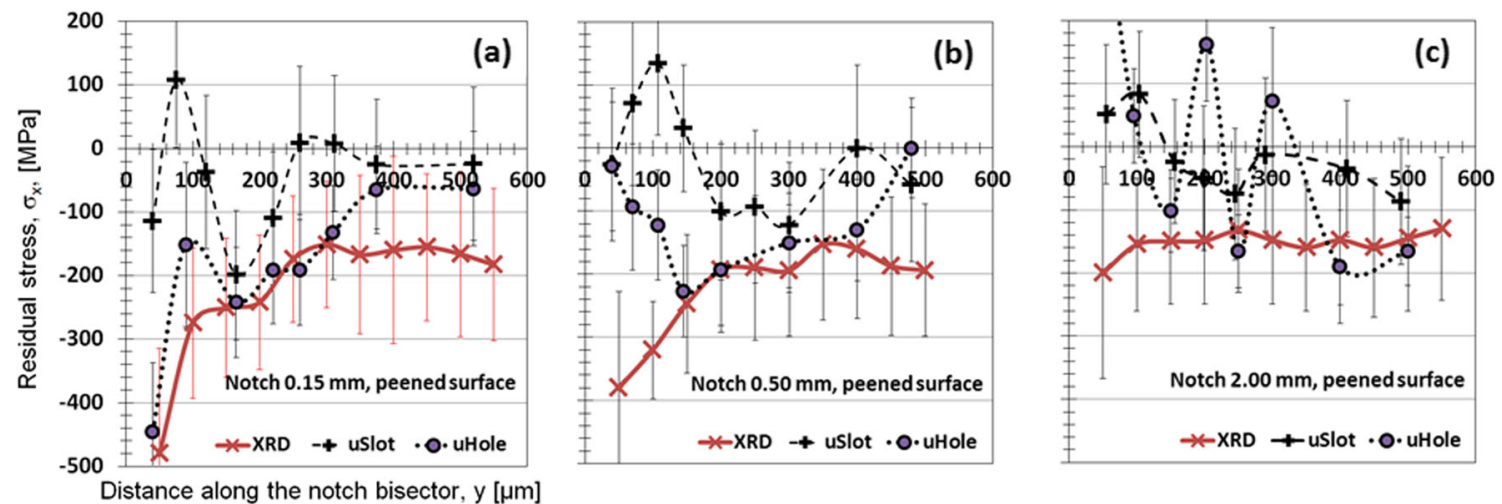

Fig. 12 Comparison between stresses $\left(\sigma_{\mathrm{x}}\right)$ measured at the peened surface $(1 \mu \mathrm{m}$ depth $)$ by $\mu \mathrm{HD}$ and $\mu \mathrm{SC}$ as well as those sampled over the penetration depth $(\sim 40 \mu \mathrm{m})$ by XRD for samples with (a) a $0.15 \mathrm{~mm}$, (b) $0.50 \mathrm{~mm}$ and (c) a $2 \mathrm{~mm}$ notch radii. Note: the distance along the notch bisector is measured from the root of notch

measured for the $\mu \mathrm{SC}$ and $\mu \mathrm{HD}$ is associated with four factors: (a) the relatively small gauge volume of both methods, which is similar to, or smaller than, the grain size. The RS would be expected to vary from grain to grain (as recently measured by $\mu \mathrm{HD}$ in [54]); (b) each grain is elastically anisotropic and this has not been accounted for here; (c) since the plastically affected depth spans below $30 \mu \mathrm{m}$ depth consequently anisotropic micro slip bands could create intergranular stresses between the grains; (d) various crystalline phases with different elasticity are present, e.g. the $\mathrm{Al}_{2} \mathrm{CuMg}$ eutectic phase precipitates are twice as stiff as the Al-rich matrix [60], and these are not taken into account in RS estimates. Since the Al-rich grains are fairly isotropic (the Zener ratio is 1.2 [54]) thus (a) and (b) may have small impact on the RSs scatter (discussed in details in [54]). Large precipitates are of the comparable size or bigger, thus the effective elastic modulus in the gauge volume is different than the matrix material and measurement taken from the immediate vicinity of large participate can be considerably altered [54].
It can be observed from Fig. 14 that both experimental techniques reveal a concentration of the longitudinal RS component at the notch root, which scales with the severity of the notch. The region where RS are affected by the notch spans over about $200 \mu \mathrm{m}$ from the notch tip. The lateral gradient of the longitudinal RS component varies between 1 and $3 \mathrm{MPa} /$ $\mu \mathrm{m}$ for the blunt and the very-sharp notched specimens, respectively. Such lateral stress gradient in a so narrow region considerable limits the experimental techniques able to resolve the detected RS distribution. Among the experimental techniques discussed in the Introduction, only synchrotron XRD possesses the necessary lateral spatial resolution and spot size, but the high penetration depth of such radiation in conjunction with the shallow in-depth RS distribution poses considerable difficulties to the applicability of this method. Even though the experimental techniques used in this paper succeeded in resolving the lateral RS gradients, the measurements are affected by considerable uncertainty and the determination of the RS at a distance smaller than $50 \mu \mathrm{m}$ from the
Fig. 13 (a) FEGSEM image showing polished surface of $\mathrm{R}=0.50$ specimen indicating the Set II SEM-FIB-DIC measurement locations; inset shows micro-hole and micro-slot with dashed line marking the location of PFIB milled crosssection (b) a PFIB cross-section revealing sub-surface severedamage-free microstructure. Note: chequered arrows show the same micro-hole and micro-slot
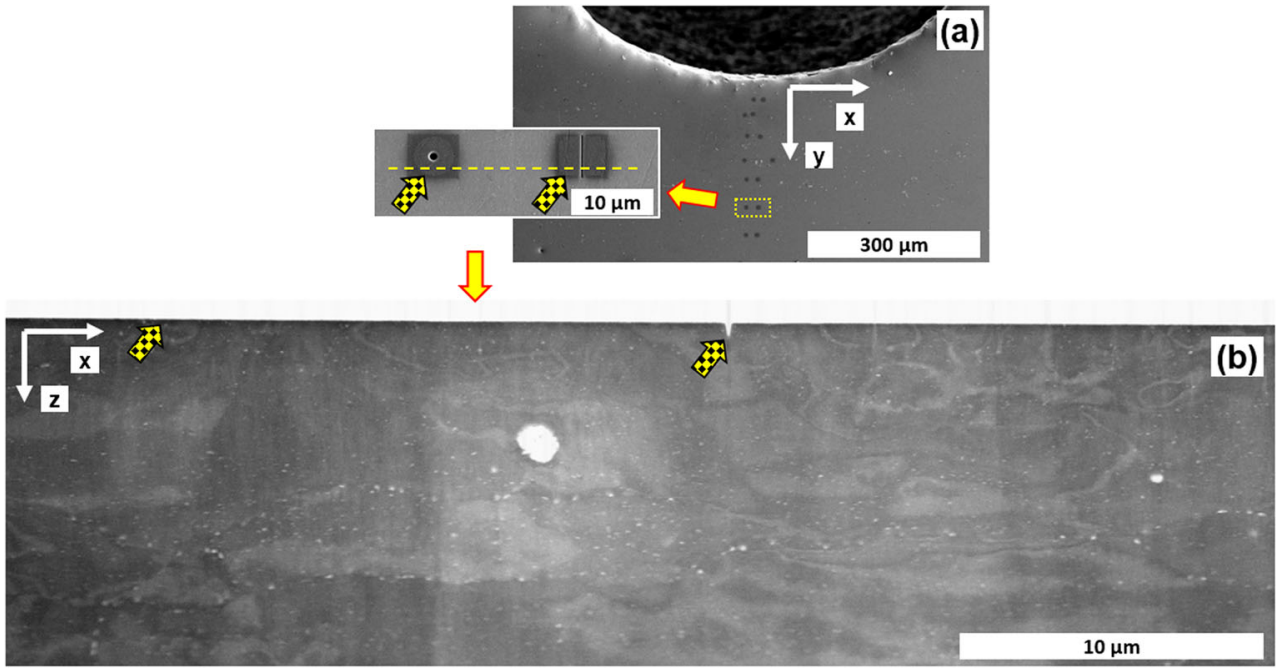

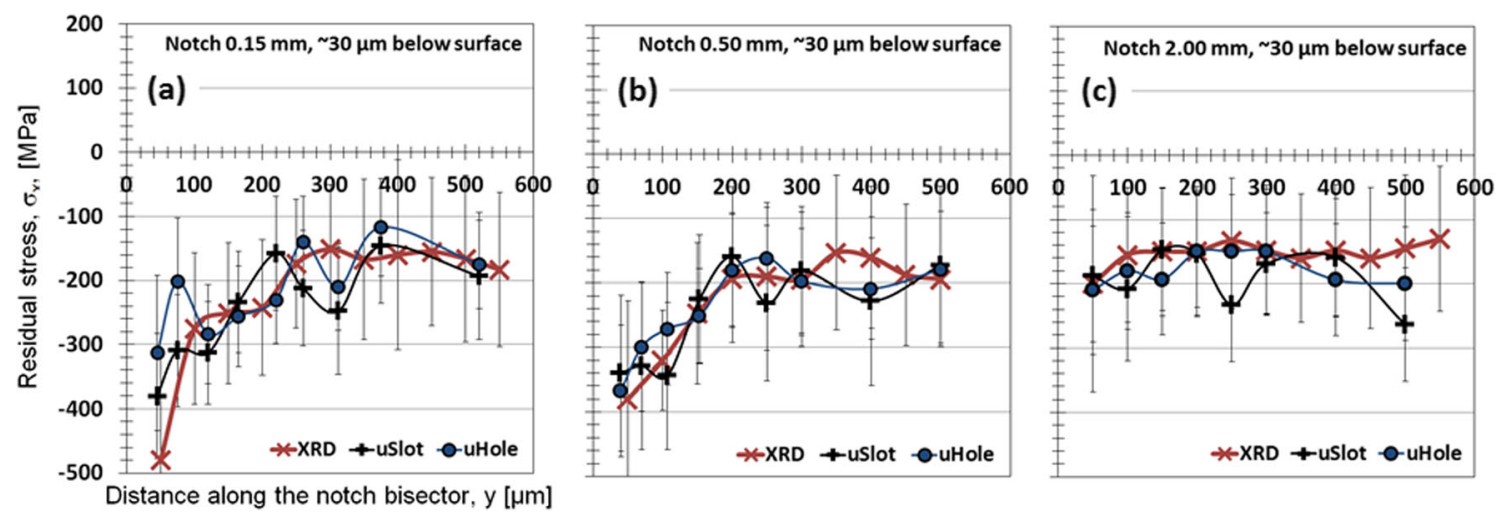

Fig. 14 Comparison of residual stresses $\left(\sigma_{\mathrm{x}}\right)$ measured $\sim 30 \mu \mathrm{m}$ below the surface (for $\mu \mathrm{SC}$ and $\mu \mathrm{HD}$ ) and measured nominally at the surface by XRD along the notch bisector for samples with (a) $0.15 \mathrm{~mm}$, (b) $0.50 \mathrm{~mm}$ and (c) $2 \mathrm{~mm}$ notch radii. Note: the distance along the notch bisector is measured from the root of notch

notch tip is impeded by the size of the X-ray beam and/or the uncertainty on the exact location of the notch apex due to the geometry distortions produced by the peening treatment. The level of confidence whereby the RS field can be reconstructed in the vicinity of the notch tip on the base of the measurements herein presented will be discussed in the companion paper [49].

\section{Conclusions}

In this paper ultra-high resolution $(\sim 0.5-0.8 \mu \mathrm{m}$ depth and $10 \mu \mathrm{m}$ lateral resolution) mechanical relaxation stress measurements were used to evaluate the stress variation local to individual peening dimples in ceramic shot peened Al-7075-T651 double notched samples having $0.15,0.5$ and $2.0 \mathrm{~mm}$ radii using Micro-Hole Drilling, Micro-Slot Cutting and micro X-ray Diffraction methods. The $\mu \mathrm{HD}$ and $\mu \mathrm{SC}$ methods have much smaller sampling volumes $(\sim 10 \mu \mathrm{m}$ laterally and $0.5-0.8 \mu \mathrm{m}$ depth $)$ than the $\mu$ XRD. Consequently, it was possible for the first time to record the heterogeneity of residual stresses $(+/-150 \mathrm{MPa})$ in the overlapping dimples caused by individual shot on the surface. Unsurprisingly, the stress is much more homogeneous at a depth of $30 \mu \mathrm{m}$ giving much smoother $\mu \mathrm{HD}$ and $\mu \mathrm{SC}$ RS profiles. While these are still affected by $(+/-50 \mathrm{MPa})$ point-to-point scatter they compare very well the $\mu \mathrm{XRD}$ measurements which sample over a depth of approximately $40 \mu \mathrm{m}$ and an area of $50 \mu \mathrm{m}$ diameter.

The analysis of the measurement clearly showed that the most critical factors to be considered when planning and performing the experimental measurements using the SEMFIB-DIC based methods are:

(a) the size of representative gauge volume and its microstructural features. In cases where, the gauge volumes are of the same size inclusions, precipitates, etc. the residual stress estimates can be altered if their different elastic properties are not accounted for in the analyses. The gauge volumes could be corrupted by existence of micro-cracks, voids, thus generating misleading stress estimates. For micron-size gauge volumes elastic anisotropic behaviour of a specimen is expected to dominate the elastic response, therefore the proper choice of the elastic modulus to be used for stress evaluations in the SEM-FIB-DIC methods represents an additional source of error. Further variations of RSs could be due to intergranular stress set up by slight misfits arising from anisotropic crystalline deformation.

(b) the depth of penetration with respect to the stress gradients. $\mu \mathrm{SC}$ and $\mu \mathrm{HD}$ methods average residual stress over the excavated depth (the penetration depth). Therefore the results obtained by these methods can be directly compared for the same penetration depth. Alternatively, for different penetration depths the incremental variants of micro-hole drilling and micro-slotting methods, i.e. I $\mu \mathrm{SC}$ [45] and I $\mu \mathrm{HD}[44]$, can be used.

Application of FEI Helios Plasma Xe $\mathrm{e}^{+}$PFIB-SEM dual beam microscope for serial sectioning tomography technique allowed 3D microstructural characterization with nanometer SEM resolution from the surface layers near the notch roots modified by the SP treatment down to parent microstructure at depths practically not achievable by $\mathrm{Ga}^{+}$FIB-SEMs. There is very good correlation between residual stress depth profile and microstructural features captured by electron channeling imaging combined with large volume SST and EBSD maps. Surface layers to about 5-8 $\mu \mathrm{m}$ deep are highly plastically deformed with a submicrometer size grains and a network of sub-surface cracks. These release residual stresses and the drop of compressive stresses is observed near the surface. At shallow depths above $10 \mu \mathrm{m}$ the plastic deformation is still very 
high, but the cracks are not present, this allows for reaching the highest compressive residual stresses (the depth of $\sim 15 \mu \mathrm{m}$ ). The compressive RSs are reduced with depth, as this is reflected by larger grains with lower electron channeling contrast (at depth $>30 \mu \mathrm{m}$ ).

Results obtained in current study show that it is possible to obtain a measure of the variation in local stresses by micro mechanical methods and that for shot peening that heterogeneity extend to a depth of around $30 \mu \mathrm{m}$ in the present case (of the order of half the plastically affected depth). Residual stresses mapped at greater depths provide a good measure of the local macro (continuum) stress. In the companion paper [49], these measurements are used to reconstruct the RS field through finite element (FE) analyses.

Acknowledgments Authors acknowledge the EPSRC for grants EP/ J021229/1 and EP/M010619/1 and BIS Capital Funding that established the Multiscale Characterisation Facility - a part of Henry Moseley X-ray Imaging Facility. We gratefully acknowledge Gary S. Schajer from University of British Columbia, Canada, Tim L. Burnett from The University of Manchester, U.K., and Ron Kelley at FEI, HBO, U.S.A. for their support during this work. We are grateful to Mr. M. Bandini (PeenService Ltd, Bologna, Italy) for performing the shot peening treatments.

Open Access This article is distributed under the terms of the Creative Commons Attribution 4.0 International License (http:// creativecommons.org/licenses/by/4.0/), which permits unrestricted use, distribution, and reproduction in any medium, provided you give appropriate credit to the original author(s) and the source, provide a link to the Creative Commons license, and indicate if changes were made.

\section{References}

1. Withers PJ, Bhadeshia HKDH (2001) Overview - residual stress part 2 - nature and origins. Mater Sci Technol 17(4):366-375

2. Daniel R, Keckes J, Matko I, Burghammer M, Mitterer C (2013) Origins of microstructure and stress gradients in nanocrystalline thin films: the role of growth parameters and self-organization. Acta Mater 61(16):6255-6266

3. Sebastiani M, Bemporad E, Carassiti F (2011) On the influence of residual stress on nano-mechanical characterization of thin coatings. J Nanosci Nanotechnol 11(10):8864-8872

4. Horsfall AB, dos Santos JMM, Soare SM, Wright NG, O'Neill AG, Bull SJ, Walton AJ, Gundlach AM, Stevenson JTM (2003) Direct measurement of residual stress in sub-micron interconnects. Semicond Sci Technol 18(11):992-996

5. Sabate N, Vogel D, Gollhardt A, Keller J, Cane C, Gracia I, Morante JR, Michel B (2006) Measurement of residual stress by slot milling with focused ion-beam equipment. J Micromech Microeng 16(2):254-259

6. Cowie W, Mannava S, McDaniel AE (1993) Laser shock peened rotor component for turbine engine rotor - has at least one stress riser in form of hole located in portion causing stress concentration. General Electric Co (Gene-C). p 10

7. Benedetti M, Fontanari V, Santus C, Bandini M (2010) Notch fatigue behaviour of shot peened high-strength aluminium alloys: experiments and predictions using a critical distance method. Int $\mathrm{J}$ Fatigue 32(10):1600-1611

8. Soady K, Mellor BG, Reed PAS (2013) Life assessment methodologies incorporating shot peening process effects; mechanistic consideration of residual stresses and strain hardening. Part 2: approaches to fatigue lifing after shot peening. Mater Sci Technol 29(6):652-664

9. Hanel B, Haiback E, Seeger T, Wirthgen G, Zenner H (2003) Analytical strength assessment of components in mechanical engineering. Forschungskuratorium Maschinenbau (FKM)

10. Benedetti M, Fontanari V, Bandini M, Taylor D (2014) Multiaxial fatigue resistance of shot peened high-strength aluminum alloys. Int J Fatigue 61:271-282

11. Bagherifard S, Colombo C, Guagliano M (2014) Application of different fatigue strength criteria to shot peened notched components. Part 1: fracture mechanics based approaches. Appl Surf Sci 289:180-187

12. Benedetti M, Fontanari V, Bandini M, Savio E (2015) High- and very high-cycle plain fatigue resistance of shot peened highstrength aluminum alloys: The role of surface morphology. Int $\mathrm{J}$ Fatigue 70:451-462

13. Xiang Y, Liu Y (2010) Mechanism modelling of shot peening effect on fatigue life prediction. Fatigue Fract Eng Mater Struct 33(2): $116-125$

14. Guagliano M, Vergani L (2004) An approach for prediction of fatigue strength of shot peened components. Eng Fract Mech 71(4-6):501-512

15. Gao Y, Yao M, Li JK (2002) An analysis of residual stress fields caused by shot peening. Metall Mater Trans A-Phys Metall Mater Sci 33(6): 1775-1778

16. Martinez S, Sathish S, Blodgett MP, Shepard MJ (2003) Residual stress distribution on surface-treated Ti-6Al-4V by x-ray diffraction. Exp Mech 43(2):141-147

17. Fontanari V, Frendo F, Bortolamedi T, Scardi P (2005) Comparison of the hole-drilling and $\mathrm{X}$-ray diffraction methods for measuring the residual stresses in shot-peened aluminium alloys. J Strain Anal Eng Des 40(2):199-209

18. Vazquez J, Navarro C, Dominguez J (2012) Experimental results in fretting fatigue with shot and laser peened Al 7075-T651 specimens. Int J Fatigue 40:143-153

19. Webster P, Mills G, Wang XD, Kang WP (1997) Synchrotron strain scanning through a peened aluminium alloy plate. Proc ICRS 5: $551-556$

20. Zhang S, Venter A, Vorster WJJ, Korsunsky AM (2008) Highenergy synchrotron X-ray analysis of residual plastic strains induced in shot-peened steel plates. J Strain Anal Eng Des 43(4): 229-241

21. Menig R, Pintschovius L, Schulze V, Vohringer O (2001) Depth profiles of macro residual stresses in thin shot peened steel plates determined by X-ray and neutron diffraction. Scr Mater 45(8):977983

22. Meguid S, Shagal G, Stranart JC (2007) Development and validation of novel $\mathrm{FE}$ models for 3D analysis of peening of strain-rate sensitive materials. J Eng Mater Technol-Trans Asme 129(2):271283

23. Majzoobi GH, Azizi R, Alavi Nia A (2005) A three-dimensional simulation of shot peening process using multiple shot impacts. J Mater Process Technol 164-165:1226-1234

24. Benedetti M, Fontanari V, Hohn BR, Oster P, Tobie T (2002) Influence of shot peening on bending tooth fatigue limit of case hardened gears. Int J Fatigue 24(11):1127-1136

25. Olmi G, Comandini M, Freddi A (2010) Fatigue on shot-peened gears: experimentation, simulation and sensitivity analyses. Strain 46(4):382-395 
26. Bergström J, Ericsson T (1984) Relaxation of shot peening induced compressive stress during fatigue of notched steel samples. in 2nd international conference on shot peening, Illinois: ICSP2

27. Buchanan D, John R (2014) Residual stress redistribution in shot peened samples subject to mechanical loading. Mater Sci Eng aStruct Mater Prop Microstruct Process 615:70-78

28. Soady K, Mellor BG, Shackleton J, Morris A, Reed PAS (2011) The effect of shot peening on notched low cycle fatigue. Mater Sci Eng a-Struct Mater Prop Microstruct Process 528(29-30):85798588

29. King A et al (2006) Effects of fatigue and fretting on residual stresses introduced by laser shock peening. Mater Sci Eng A-Struct Mater Prop Microstruct Process 435:12-18

30. Jun T, Venter AM, Korsunsky AM (2011) Inverse eigenstrain analysis of the effect of Non-uniform sample shape on the residual stress due to shot peening. Exp Mech 51(2):165-174

31. Achintha M, Nowell D, Fufari D, Sackett EE, Bache MR (2014) Fatigue behaviour of geometric features subjected to laser shock peening: experiments and modelling. Int J Fatigue 62:171-179

32. Schajer GS, Prime MB (2007) Residual stress solution extrapolation for the slitting method using equilibrium constraints. J Eng Mater Technol-Trans Asme 129(2):227-232

33. Prime MB (2000) The contour method: simple 2-D mapping of residual stresses. Am Soc Mech Eng, Press Vessel Pip Div (Publication) PVP 415:121-127

34. Schajer GS (2009) Advances in hole-drilling residual stress measurements. Exp Mech 50(2):159-168

35. Noyan IC, Cohen JB (1987) Residual stress:- measurement by diffraction and interpretation. Springer, New York

36. Fitzpatrick M, Lodini A (2003) Analysis of residual stress by diffraction using neutron and synchrotron radiation. Taylor \& Francis, London

37. James M, Hattingh DG, Hughes DJ, Wei LW, Patterson EA, De Fonseca JQ (2004) Synchrotron diffraction investigation of the distribution and influence of residual stresses in fatigue. Fatigue Fract Eng Mater Struct 27(7):609-622

38. Croft M, Zhong Z, Jisrawi N, Zakharchenko I, Holtz RL, Skaritka J, Fast T, Sadananda K, Lakshmipathy M, Tsakalakos T (2005) Strain profiling of fatigue crack overload effects using energy dispersive X-ray diffraction. Int J Fatigue 27(10-12):1408-1419

39. Korsunsky A, Song X, Belnoue J, Jun T, Hofmann F, De Matos PFP, Nowell D, Dini D, Aparicio-Blanco O, Walsh MJ (2009) Crack tip deformation fields and fatigue crack growth rates in Ti6Al-4V. Int J Fatigue 31(11-12):1771-1779

40. Steuwer A, Rahman M, Shterenlikht A, Fitzpatrick ME, Edwards L, Withers PJ (2010) The evolution of crack-tip stresses during a fatigue overload event. Acta Mater 58(11):4039-4052

41. Schajer GS, Winiarski B, Withers PJ (2013) Hole-drilling residual stress measurement with artifact correction using full-field DIC. Exp Mech 53(2):255-265

42. Winiarski B, Withers PJ (2010) Mapping residual stress profiles at the micron scale using FIB micro-hole drilling. Appl Mech Mater 24-25:267-272

43. Winiarski B, Langford RM, Tian J, Yokoyama Y, Liaw PK, Withers PJ (2009) Mapping residual-stress distributions at the micron scale in amorphous materials. Metall Mater Trans A 41:1743-1751
44. Winiarski B, Withers PJ (2012) Micron-scale residual stress measurement by micro-hole drilling and digital image correlation. Exp Mech 52(4):417-428

45. Winiarski B, Gholinia A, Tian J, Yokoyama Y, Liaw PK, Withers PJ (2012) Submicron-scale depth profiling of residual stress in amorphous materials by incremental focused ion beam slotting. Acta Mater 60(5):2337-2349

46. Winiarski B, Withers PJ (2015) Novel implementations of relaxation methods for measuring residual stresses at the micron scale. J Strain Anal Eng Des 50(7):412-425

47. Allahkarami M, Hanan JC (2011) Mapping the tetragonal to monoclinic phase transformation in zirconia core dental crowns. Dent Mater 27(12):1279-1284

48. Korsunsky A, Sebastiani M, Bemporad E (2010) Residual stress evaluation at the micrometer scale: analysis of thin coatings by FIB milling and digital image correlation. Surf Coat Technol 205(7): 2393-2403

49. Benedetti M, Fontanari V, Winiarski B, Allahkarami M, Hanan JC (2016) Residual stresses reconstruction in shot peened specimens containing sharp and blunt notches by experimental measurements and finite element analysis. Int J Fatigue 87:102-111

50. Benedetti M, Fontanari V, Scardi P, Ricardo CLA, Bandini M (2009) Reverse bending fatigue of shot peened 7075-T651 aluminium alloy: the role of residual stress relaxation. Int J Fatigue 31(89):1225-1236

51. Oguri K (2011) Fatigue life enhancement of aluminum alloy for aircraft by Fine Particle Shot Peening (FPSP). J Mater Process Technol 211(8):1395-1399

52. He B (2009) Two-dimensional X-ray diffraction. Wiley, Hoboken

53. Winiarski B, Schajer GS, Withers PJ (2012) Surface decoration for improving the accuracy of displacement measurements by digital image correlation in SEM. Exp Mech 52(7):793-804

54. Winiarski B, Withers PJ (2014) Mapping stresses within Grains by the Micro-slot Cutting Method. in SEM 2014 Annual Meeting \& Exposition. Greenville

55. Tada H, Paris P, Irwin G (1973) The stress analysis of cracks handbook. Del Research Corporation, Michigan

56. Guz A (2000) Description and study of some nonclassical problems of fracture mechanics and related mechanisms. Int Appl Mech 36(12):1537-1564

57. Nastasi M, Mayer JW (2006) Ion implantation and synthesis of materials. Springer, Berlin Heidelberg

58. Burnett TL, Kelley R, Winiarski B, Contreras L, Daly M, Gholinia A, Burke MG, Withers PJ (2016) Large volume serial section tomography by Xe Plasma FIB dual beam microscopy. Ultramicroscopy 161:119-129

59. Xiong YS, Withers PJ (2006) A deconvolution method for the reconstruction of underlying profiles measured using large sampling volumes. J Appl Crystallogr 39:410-424

60. Zhang J, Huang YN, Mao C, Peng P (2012) Structural, elastic and electronic properties of $\theta(\mathrm{Al} 2 \mathrm{Cu})$ and $\mathrm{S}(\mathrm{Al} 2 \mathrm{CuMg})$ strengthening precipitates in $\mathrm{Al}-\mathrm{Cu}-\mathrm{Mg}$ series alloys: first-principles calculations. Solid State Commun 152(23):2100-2104 